\title{
Surgical Treatment of Patients with Bilateral Atherosclerotic Lesions of Carotid Arteries
}

\author{
Shavkat I. Karimov, MD,ScD; Ravshan D. Sunnatov, MD,PhD; Rustam T. Muminov, MD*; \\ Akmal A. Irnazarov, MD,PhD; Abdurasul A. Yulbarisov, MD,PhD; Dilmurad A. Ganiyev, \\ MD,PhD; Uktamkhon A. Asrarov, MD, PhD; Khojiakbar K. Alidzhanov, MD \\ Tashkent Medical Academy, Tashkent, Uzbekistan
}

\begin{abstract}
The objective of study was to improve the results of surgical treatment of patients with bilateral atherosclerotic lesions of the carotid arteries.

Material and Methods: The study included 180 patients between the ages of 42 and 82 (mean age $59 \pm 5.6$ yrs) who underwent surgical treatment for bilateral atherosclerotic lesions of the carotid arteries during 2008-2014. Depending on the surgical treatment tactic, a total of 180 patients were divided into two groups. Group 1 included 60 (33.3\%) patients who underwent staged bilateral carotid endarterectomy (CEA). Group 2 included 120 (66.7\%) patients, in whom the first stage of CEA was performed on the side of primary importance.

Results: The differentiated approach for identification the side for the first stage CEA is very important. Our experience shows that the intervals between CEA on both sides should not exceed 3 months and should be no less than 3 weeks. This tactic reduces not only mortality and complications, but also significantly improves the patient life quality by promoting rapid regression of neurological deficit.
\end{abstract}

Keywords: bilateral atherosclerotic lesions; carotid arteries; staged bilateral carotid endarterectomy.

\section{Introduction}

Atherosclerotic lesions of the brachiocephalic arteries are one of the main reasons of acute and transient brain circulation disorders [1-6]. Bilateral atherosclerotic lesions of carotid arteries are more usual then isolated lesions [7-8]. The most reliable and effective method for the prevention of stroke that is caused by atherosclerosis of carotid arteries is carotid endarterectomy (CEA). It is important to study the cerebral hemodynamics before planning intervention [9-11]. According to some authors, it is necessary to focus not only on the degree of stenosis but mainly on the embologenic properties of atherosclerotic plaque (ASP) [12-14].

Although, some questions have not been answered yet, namely criteria to be used for determining surgical tactics, the stages, and the sequence of the operations and the intervals between them? It should be borne in mind that a one-sided

*Corresponding author: Rustam T. Muminov, MD. Department of Surgery, Tashkent Medical Academy. Tashkent, Uzbekistan E-mail: aziatru85@mail.ru approach that considers the hemodynamic importance of the lesions only or the carotid pool with the prevalent carotid symptoms, is hopeless and fraught with serious consequences [15]. In connection with this, it is necessary to have a specific tactic in choosing a side with primary importance for CEA performance.

Taking into account the above-mentioned considerations, the aim of our study was to improve the results of the surgical treatment for patients with bilateral atherosclerotic lesions of the carotid arteries by determining the optimal time frame and the stages of the carotid reconstruction.

\section{Material and Methods}

The study included 180 patients between the ages of

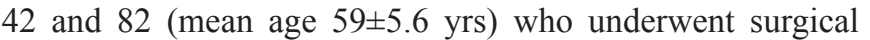
treatment for bilateral atherosclerotic lesions of the carotid arteries during 2008-2014. Written informed consent was obtained from each patient. Depending on the surgical treatment tactic, a total of 180 patients were divided into two groups. Group 1 included 60/33.3\% patients who underwent 
staged bilateral CEA. Group 2 included 120/66.7\% patients, in whom the first stage of CEA was performed on the side of a primary importance. Patients of both groups did not differ significantly in mean age and sex.

A duplex scan (DS) was performed in all patients, using Samsung Medison SonoAce X6 (South Korea, 2008). The diameter of common carotid artery (CCA), the internal carotid artery (ICA), and external carotid artery (ECA), as well as CCA intima-media thickness (IMT) cerebral blood flow velocity $(\mathrm{CBFV})$, the pulsatility index (PI) and resistance index (RI) were measured.

The ECST method of measuring carotid stenosis was applied [2]. All patients underwent duplex imaging investigation with identification of the percentage of stenosis, velocity and direction of the blood flow, and the structure of plaques. For a description of ASP, the GrayWeale classification was used [16]. The volume velocity in the brachiocephalic arteries was measured at extracranial and intracranial levels. The volume velocity in CCA, ICA, ECA, and the vertebral artery was measured three times on each side, and then the average volume velocity was calculated on the left and right side of each patient. Hemodynamics in the intracranial arteries was analyzed using the analogical method for calculating average volume velocity. Performing transcranial duplex imaging, we paid attention to the blood flow direction and velocity in the MCA; compression tests for estimating the communicant arteries were also carried out. CT scans of the brain were performed in all patients to estimate the nature and localization of the brain lesions.

All patients were examined by a neurologist before and after intervention, during both the short and long postoperative periods. For quantifying neurological deficit in patients with ischemic stroke or transient ischemic attack (TIA), the Hachinski Ischemic Scale scale was used [17].

Statistical analysis was performed using the statistical software «Statistica». Data significance was assessed by the Student's t-test. Statistical significance was determined at $P<0.05$.

\section{Results and Discussion}

According to the A.V. Pokrovskiir classification, the patients of both groups were divided into stages of chronic cerebrovascular insufficiency (CCVI) (Table 1). In both groups, the stroke patients dominated.

\section{Table 1.}

Stages of chronic cerebrovascular insufficiency

\begin{tabular}{|l|c|c|c|}
\hline \multirow{2}{*}{ Stages of CCVI } & \multicolumn{2}{|c|}{ Number of the patients } & Total \\
\cline { 2 - 3 } & $\begin{array}{c}\text { Group 1 } \\
(\mathrm{n}=60)\end{array}$ & $\begin{array}{c}\text { Group 2 } \\
(\mathrm{n}=120)\end{array}$ & \\
\hline Asymptomatic CCVI & $3(5.0 \%)$ & $7(5.8 \%)$ & 5.6 \\
\hline TIA & $12(20.0 \%)$ & $23(19.2 \%)$ & 19.4 \\
\hline Discirculatory encephalopathy & $20(33.3 \%)$ & $42(35.0 \%)$ & 34.4 \\
\hline Consequences of ischemic stroke & $25(41.7 \%)$ & $48(40.0 \%)$ & 40.6 \\
\hline Total & \multicolumn{2}{|c|}{180} & 100 \\
\hline
\end{tabular}

According to the type of carotid reconstructions performed, patients of both groups were similar; in both groups the technical procedures of the operations were identical (Table 2). In total of 296 CEA were performed.

Table 2.

Types of of carotid reconstructions

\begin{tabular}{|l|c|c|c|c|c|}
\hline \multirow{2}{*}{ Name of operation } & \multicolumn{5}{|c|}{ Quantity of procedures } \\
\cline { 2 - 5 } & \multicolumn{2}{|c|}{$\begin{array}{c}\text { Group 1 } \\
(\mathrm{n}=117)\end{array}$} & \multicolumn{2}{|c|}{$\begin{array}{c}\text { Group 2 } \\
(\mathrm{n}=200)\end{array}$} & $\begin{array}{c}\text { Total } \\
(\mathrm{n}=317)\end{array}$ \\
\cline { 2 - 5 } & 1 stage & 2 stage & 1 stage & 2 stage & \\
\hline CEA with patch & 30 & 33 & 41 & 59 & 166 \\
\hline Eversion CEA & 21 & 24 & 44 & 41 & 130 \\
\hline ICA bypass grafting & 1 & - & - & - & 1 \\
\hline ECA plasty & 8 & - & 15 & & 23 \\
\hline
\end{tabular}

Group 1 patients underwent staged bilateral CEA. In patients with ischemic stroke, in determining the side for the carotid reconstruction, the preference was given to the appropriate carotid pool; the degree of stenosis played a secondary role. Twenty-two (36.7\%) patients underwent CEA on the side of the ischemic episode. In $23(38.3 \%)$ cases, the patients with discirculatory encephalopathy and asymptomatic patients underwent CEA on the side with a higher degree of stenosis. Most patients with TIA at the first stage intervention underwent CEA on the side of the ischemic episode regardless of the degree of stenosis on the contralateral side. Among patients in this group, unstable ASP was detected in $12(20.0 \%)$ cases. The patients $(8 / 13.3 \%)$ with ICA occlusion at the first stage intervention underwent CEA on the side of the ischemic episode regardless of the degree of stenosis on the contralateral side. Three $(5.0 \%)$ patients with ICA occlusion underwent CEA on the contralateral side because of ischemic stroke in that carotid pool. The time frame of carotid reconstruction on the contralateral side varied from 2 weeks to 2 years (average period 5.2 months). Thirty-two (53.3\%) patients of Group 1 underwent CEA within 6 months.

The analysis revealed a pronounced association between the clinical effect of the operation and the initial level of the neurological deficit, as well as time frame from stroke and time frame of the second stage of carotid reconstruction. The first stage of CEA was performed in $14 / 56.0 \%$ patients with a mild degree of neurological deficit, in $6 / 24.0 \%$ patients with a moderate degree of neurological deficit, and in 5/20.0\% patients with a severe degree of neurological deficit.

Absolute increase in scores among different levels of neurological deficit was not the same for all patients. The highest rate of neurological deficit involution was observed in patients with a mild to moderate degree of neurological deficit, and who were operated on within 6 months of a stroke, and also in patients who underwent the procedure on the contralateral side within 2 or 3 months. According to the Hachinski Ischemic Scale, an increase of points in patients with mild, moderate, and severe degrees of neurological deficit was 29.2, 17.1, and 4.4, respectively.

In Group 1, the total complication rate was 5.0\%. Ischemic stroke occurred in one (1.7\%) patient in the carotid 
artery operation pool after 30 days from the first stage of CEA. Neurological deficit totally disappeared during 15 days. On the contralateral side, SEA was performed after 2 months, and the patient was discharged in satisfactory condition. Perioperative ischemic stroke occurred in one patient with occluded ICA on the contralateral side. In one $(1.7 \%)$ patient with a local occlusion of the left ICA and a complete occlusion of the right ICA, staged bilateral CEA was performed with an interval of 2 weeks because of frequent TIA on the contralateral side. This patient underwent hemorrhagic stroke after the 2nd stage of CEA. We suppose that this stroke resulted from irregular taking of hypotensive drugs and the development of the cerebral hyperperfusion syndrome after discharge from the hospital.

In Group 2 patients, the differentiated approach was performed to identify the side of primary importance in determining the indications for reconstruction. The severity of of the atherosclerotic lesions in the carotid pool was taken into account. Particular attention was paid to total stenosis of the carotid arteries and the volume velocity in the extraand intracranial cerebral arteries while taking into account the adapted flow redistribution and the brain's tolerance to ischemia. The structure, surface and spread of the plaque according to the data of DS and MSCTA were also considered. The remoteness of the ischemic episode, and the severity and speed of the regress of neurological deficit were taken into account in patients with ischemic stroke in anamnesis. Thus, the preference was given to the side of the occlusion for the first stage of CEA in patients with occlusion of ICA and the opposite critical stenosis.

For an objective assessment of the carotid pool, we developed and applied the estimated scale of the severity of the carotid artery pool lesions (Table 3). Every lesion parameter was estimated in points. The first stage of CEA was performed on the side with the highest number of points that corresponded to the greatest lesion of the carotid artery pool. Two hundred CEAs were performed in Group 2 patients, and each case was considered independently. The timing for performing CEA on the contralateral side varied from 2 to 3 months.

The clinical effect of surgery was significantly increased by the identification of the most affected carotid pool and the choice of the optimal time frame for CEA on the contralateral side. Also in 22/18.3\% patients with low brain tolerance to ischemia and severe lesions of carotid arteries on both sides and in patients with stroke we used an intra-arterial temporary shunt. In the cases of temporary shunting, a mean time of ischemia was $7 \pm 2 \mathrm{~min}$, which was necessary to perform CEA, insert the shunt, and complete anastomosis.

At the first stage of CEA, 20/41.6\% patients had a mild degree of neurological deficit; $22 / 45.8 \%$ patients, a moderate degree; and $6 / 12.5 \%$ patients, a severe degree. A full regress of the neurologic symptoms took place in $16 / 33.3 \%$ patients after CEA had been performed on the opposite side, and 3/6.2\% patients passed from a moderate degree to a mild degree of neurological deficit.

In Group 2, the total complication rate was $1.7 \%$. Ischemic stroke occurred in one patient after 5 months from the second stage of CEA. We believe that ischemic stroke was connected with discontinuation of hypotensive drugs and antiplatelats. It is necessary to underline that such complications as stroke and mortality were not detected in 30 days after 2 nd stage CEA in this group of the patients.

Table 3.

The estimated scale of the severity of the carotid artery pool lesions

\begin{tabular}{|c|c|c|c|}
\hline \multicolumn{4}{|c|}{ Variables } \\
\hline On the right & Points & On the left & Points \\
\hline \begin{tabular}{|l|} 
1.Degree of stenosis \\
$55-70 \%$ \\
$70-99 \%$ \\
Occlusion \\
\end{tabular} & $\begin{array}{l}1 \\
2 \\
3\end{array}$ & \begin{tabular}{|l} 
1.Degree of stenosis \\
$55-70 \%$ \\
$70-99 \%$ \\
Occlusion \\
\end{tabular} & $\begin{array}{l}1 \\
2 \\
3\end{array}$ \\
\hline $\begin{array}{l}\text { 2. Stroke (terms) and TIA } \\
\text { TIA } \\
<6 \text { months } \\
>6 \text { months }\end{array}$ & $\begin{array}{l}3 \\
2 \\
1\end{array}$ & $\begin{array}{l}\text { 2. Stroke (terms) and TIA } \\
\text { TIA } \\
<6 \text { months } \\
>6 \text { months }\end{array}$ & $\begin{array}{l}3 \\
2 \\
1\end{array}$ \\
\hline $\begin{array}{l}\text { 3. Neurologic deficit } \\
\text { Permanent } \\
\text { Hidden } \\
\text { Progressive }\end{array}$ & $\begin{array}{l}1 \\
2 \\
3\end{array}$ & $\begin{array}{l}\text { 3. Neurologic deficit } \\
\text { Permanent } \\
\text { Hidden } \\
\text { Progressive }\end{array}$ & $\begin{array}{l}1 \\
2 \\
3\end{array}$ \\
\hline $\begin{array}{l}\text { 4. Number of the strokes } \\
\text { (in anamnesis) } \\
1 \\
2 \\
>2\end{array}$ & $\begin{array}{l}1 \\
2 \\
3\end{array}$ & $\begin{array}{l}\text { 4. Number of the strokes } \\
\text { (in anamnesis): } \\
1 \\
2 \\
>2\end{array}$ & $\begin{array}{l}1 \\
2 \\
3\end{array}$ \\
\hline $\begin{array}{l}\text { 5. Brain CT (sizes of the } \\
\text { focus): } \\
\quad<3 \mathrm{~cm} \\
<6 \mathrm{~cm} \\
>6 \mathrm{~cm}\end{array}$ & $\begin{array}{l}3 \\
2 \\
1\end{array}$ & $\begin{array}{l}\text { 5. Brain CT (sizes of the } \\
\text { focus): } \\
\quad<3 \mathrm{~cm} \\
<6 \mathrm{~cm} \\
>6 \mathrm{~cm}\end{array}$ & $\begin{array}{l}3 \\
2 \\
1\end{array}$ \\
\hline $\begin{array}{l}\text { 6. ASP features: } \\
\text { Stabile } \\
\text { Occlusion } \\
\text { Embologenous }\end{array}$ & $\begin{array}{l}1 \\
2 \\
3\end{array}$ & $\begin{array}{l}\text { 6. ASP features: } \\
\text { Stabile } \\
\text { Occlusion } \\
\text { Embologenous }\end{array}$ & $\begin{array}{l}1 \\
2 \\
3\end{array}$ \\
\hline $\begin{array}{l}\text { 7. Deficit of total cerebral } \\
\text { blood flow } \\
1 \text { degree } \\
2 \text { degree } \\
3 \text { degree } \\
\end{array}$ & $\begin{array}{l}1 \\
2 \\
3\end{array}$ & $\begin{array}{l}\text { 7. Deficit of total cerebral } \\
\text { blood flow } \\
1 \text { degree } \\
2 \text { degree } \\
3 \text { degree }\end{array}$ & $\begin{array}{l}1 \\
2 \\
3\end{array}$ \\
\hline $\begin{array}{l}\text { 8. Compensation in the } \\
\text { MCA during the clamped } \\
\text { trials } \\
\text { Bad } \\
\text { Satisfactory } \\
\text { Good }\end{array}$ & $\begin{array}{l}1 \\
2 \\
3\end{array}$ & $\begin{array}{l}\text { 8. Compensation in the } \\
\text { MCA during the clamped } \\
\text { trials } \\
\text { Bad } \\
\text { Satisfactory } \\
\text { Good }\end{array}$ & $\begin{array}{l}1 \\
2 \\
3\end{array}$ \\
\hline
\end{tabular}

The identification of the most important side for CEA with detection of the severity of the carotid artery pool lesion helped to reduce the complications connected with the stroke in 6 months after 2nd stage CEA from 5\% to 1.7\% (Table 4).

Table 4.

Character of complications

\begin{tabular}{|l|c|c|c|}
\hline Complications & Group 1 & Group 2 & Total \\
\hline Stroke on the atipsilateral side & $2(3.3 \%)$ & $1(0.83 \%)$ & $3(1.7 \%)$ \\
\hline Stroke on the contralateral side & $1(1.7 \%)$ & $1(0.83 \%)$ & $1(0.5 \%)$ \\
\hline "Stroke+mortality" & $1(1.7 \%)$ & - & $1(0.5 \%)$ \\
\hline Total & $3(5.0 \%)$ & $2(1.7 \%)$ & $4(2.2 \%)$ \\
\hline
\end{tabular}

The differentiated approach for identifying the side for the first stage CEA is very important. Our experience 
shows that the intervals between CEA on both sides should not exceed 3 months and should be no less than 3 weeks. This tactic not only reduces mortality and complications, but also significantly improves the patient's quality of life by promoting rapid regression of ND. Determining the stages and timing of carotid reconstruction is very important. Choosing the side with more pronounced stenosis for the first stage of EAS contributed to the reduction of complications associated with stroke from $5.0 \%$ to $1.7 \%$.

\section{Competing interests} interests.

The authors declare that they have no competing

\section{References}

1. Bladin CF, Alexandrov AV, Murphy J, Maggisano R, Norris JW. Carotid stenosis index. A new method of measuring internal carotid artery stenosis. Stroke 1995; 26(2):230-4.

2. MRC European Carotid Surgery Trial: interim results for symptomatic patients with severe (70-99\%) or with mild (0-29\%) carotid stenosis. European Carotid Surgery Trialists' Collaborative Group. Lancet 1991; 337(8752):1235-43.

3. Gay JL, Curtil A, Buffiere S, Favre JP, Barral X. Urgent carotid artery repair: retrospective study of 21 cases. AnnVasc Surg 2002; 16(4):401-6.

4. Rantner B, Pavelka M, Posch L, Schmidauer C, Fraedrich G. Carotid endarterectomy after ischemic stroke - is there a justification for delayed surgery? Eur J Vasc Endovasc Surg 2005; 30(1):36-40.

5. Rothwell PM, Eliasziw M, Gutnikov SA, Warlow CP, Barnett HJ; Carotid Endarterectomy Trialists Collaboration. Endarterectomy for symptomatic carotid stenosis in relation to clinical subgroups and timing of surgery. Lancet 2004; 363(9413):915-24.
6. Sillesen H, Nielsen T. Clinical significance of intraplaque hemorrhage in carotid artery disease. J Neuroimaging 1998; 8(1)15-9.

7. Bossema EP, Brand AN, Geenen R, Moll FL, Ackerstaff RG, van Doornen LJ. Effect of carotid endarterectomy on patient evaluations of cognitive functioning and mental and physical health. Ann Vasc Surg 2005; 19(5):673-7.

8. North American Symptomatic Carotid Endarterectomy Trial Collaborators. Beneficial effect of carotid endarterectomy in symptomatic patients with high-grade carotid stenosis. $\mathrm{N}$ Engl J Med 1991; 325(7):445-53.

9. Gavrilenko AV, Kuklin AV, Kravchenko AA, Agafonov IN. Preventive maintenance of repeated ischemic insults. Angiol Sosud Khir 2008; 14(3):143-7. [Article in Russian]. 10. Gavrilenko AV, Kuklin AV, Kiseleva TN. Efficacy of carotid endarterectomy in patients with stenosis of carotid arteries and acute vision impairment. Angiol Sosud Khir. 2013;19(1):106-12. [Article in Russian].

11. Zhulev NM, Sokurenko G, Kandyba D. Stroke of extracranial origin. Monograph. St. Petersburg; 2004.

12. Ivanova NE. Stroke prevention, diagnosis and treatment. Monograph. St. Petersburg, 2002.

13. Kazanchian PO, Popov VA, Rudakov TV. Plastic repair of the carotid artery in carotid endarterectomy. Vestn Khir Im I I Grek. 1995;154(2):9-13.[Article in Russian].

14. Miklashevich ER, Antonov G, Mitroshin GE. Carotid revascularization in acute ischemic stroke. J Cardiovasc Surg 2003; 4(10)38-9.

15. Pokrovski1 AV, Beloiartsev DF, Fedorov EE. Remote results after prosthetic repair of the internal carotid artery for atherosclerotic lesions. Angiol Sosud Khir 2009; 15(4):87-97. 16. Gray-Weale AC, Graham JC, Burnett JR, Bryne K, Lusby RJ. Carotid artery atheroma: comparison of preoperative B-mode ultrasound appearance with carotid endarterectomy specimen pathology. J Cardiovasc Surg 1988;29(6):676-81

17. Hachinski VC, Iliff LD, Zilhka E, Du Boulay GH, McAllister VL, Marshall J, et al. Cerebral blood flow in dementia. Arch Neurol 1975; 32(9):632-7. 